\title{
REFORMAS EDUCACIONAIS NEOLIBERAIS NO BRASIL E A NEGAÇÃO DA CIDADANIA DOS TRABALHADORES DOCENTES*
}

Hugo Leonardo Fonseca da Silva**

\section{RESUMO}

Este artigo tem como objetivo discutir os impactos das reformas educacionais brasileiras, desenvolvidas desde a década de 90 , sobre a construção da cidadania dos trabalhadores docentes. Para isso, busco situar as reformas educacionais num contexto mais amplo de crise do capital e de reestruturação de suas formas de exploração, bem como das reformas do Estado envidadas pelas políticas neoliberais, responsáveis pela destruição dos direitos conquistados pelos trabalhadores. Busco, ainda, refletir sobre as contradições do discurso acerca da relação educação e cidadania. E, por fim, aponto a construção da cidadania como produto da luta de classes e a produção da cidadania do trabalhador docente como resultado das lutas político-sindicais por uma educação pública, gratuita, estatal e de qualidade para as maiorias.

Palavras-chave: Trabalho docente. Cidadania. Reformas educacionais. Organização política.

\section{CRISE DO CAPITAL, NEOLIBERALISMO E A NEGAÇ̃̃o DA CIDADANIA}

A partir do final da década de 80 , o processo de redemocratização do país começa a se dissolver diante da realidade pragmática e excludente que caracteriza a rota neoliberal iniciada pelo bonapartismo tupiniquim de Collor, aprofundada pela retórica e política modernizantes de FHC e seguindo a passos firmes pelo atual governo do Partido dos Trabalhadores

\footnotetext{
* Recebido em 12/12/2007 e aprovado em 17/04/2008.

** Mestre em Educação, professor do Centro de Ensino e Pesquisa Aplicada à Educação (Cepae /UFG). E-mail: hgleofs@gmail.com
} 
(ANTUNES, 2004). As políticas e o ideário neoliberais têm apresentado um recorte muito preciso que afeta, objetiva e subjetivamente, aqueles que vivem do trabalho. O desmonte do parque produtivo nacional, os ajustes fiscais do Estado, a destruição das conquistas sociais dos trabalhadores e de seus direitos, a minimização do Estado e maximização dos setores privados em áreas essenciais (previdência, saúde, educação), bem como as crescentes taxas de desemprego estrutural e emprego precarizado são componentes concretos da atual conjuntura que evidenciam o esgotamento da capacidade civilizatória do modo de produção capitalista como analisam Wallerstein (2001) e Meszáros (2002).

As manifestações dos apologetas neoliberais e da intelligentsia da ordem apontam que estamos em uma nova era, um novo momento histórico em que não existe mais conflito entre classes (pois não existe nem mesmo classes), mas sim conflitos étnicos, religiosos e culturais e, portanto, é preciso produzir uma cultura da tolerância. Segundo os teóricos do consenso, a história chegou ao seu fim. Com a queda do sistema soviético, o esgotamento do Estado-de-bem-estar e a cooptação e postura defensiva dos movimentos anti-sistêmicos (sindicatos, partidos classistas, movimentos sociais urbanos e rurais), afirma-se categoricamente (e cinicamente) que a sociedade está a construir uma "nova" ordem marcada pelo triunfo do capital.

A produção de um misticismo ideológico sobre as maravilhas da ciência e tecnologia, da "redução" do esforço humano no trabalho (tripallium) e de uma nova razão forjada sob a insígnia da pós-modernidade que enfatiza o efêmero, o fenomênico, as circunstâncias, o individualismo narcísico e a impossibilidade de compreender e explicar racionalmente a realidade (CHAUI, 2001, p. 130-131) são constructos teórico-ideológicos que buscam formular um consenso, um novo pacto social, em que a sociabilidade capitalista seja compreendida como permanente e universal.

A tese de que o sistema do capital seja, segundo o pensamento hegemônico, o modelo mais desenvolvido, o estágio final dos modos de produzir a vida social, remete ao idealismo hegeliano que se configura como a primeira concepção global do fim da história. Segundo Meszáros (2002, p. 57), o pensamento de Hegel, extremamente marcado pela sua posição de classe, enxergou nas instituições burguesas, que insurgiam, instrumentos do "Espírito do Mundo" agindo na construção de uma ordem perfeita e racional. 
Daí sua mensagem [de Hegel] de que tínhamos chegado ao estágio histórico final, além do qual seria inconcebível sequer tentar prosseguir sem a autocontradição, pois o que até então fora realizado não resultava de um empreendimento humano limitado, mas era a jornada - prevista desde o início - da auto-realização do Espírito do Mundo, culminando, no plano do esforço humano, na ordem última do capital permanente universal.

A produção de argumentos ideológicos que objetivam justificar e produzir um consenso em torno da inevitabilidade, universalidade e imutabilidade da ordem social capitalista se estende ao longo da história e toma um rumo diferenciado durante a denominada crise estrutural do capital (ANTUNEs, 2002), que se arrasta desde meados da década de 70. O debate, encaminhado pelo pensamento hegemônico sobre os rumos da sociedade, afirma que não há alternativa e que é preciso subordinar todos e tudo aos imperativos do capital. É necessário aperfeiçoá-lo, remodelá-lo, maquiá-lo, mas não superá-lo. As teses de que estamos numa era pós-industrial, na era do acesso à virtualidade, numa sociedade do conhecimento sem classes, sem trabalho e nem mesmo história, afirmam o cinismo ideológico das idéias, pensamentos e representações de uma determinada classe apresentadas como verdade universal e absoluta, como afirmara Marx e Engels (1999) em A ideologia alemã.

Os argumentos burgueses de que a materialização de uma sociedade marcada pelos instrumentos democratizantes, racionais e políticos do Estado moderno e das instituições sociais são os pressupostos necessários à realização da liberdade e igualdade entre todos os homens e mulheres têm se constituído como ideologia hegemônica - no sentido marxiano de falsa consciência - co-responsável pela reprodução e expansão das relações sociais capitalistas. Tais idéias são apresentadas como que descoladas de sua base material, desconexas do âmbito das relações sociais de produção e da divisão social hierárquica do trabalho, separando as dimensões políticas das dimensões da economia, fetichizando, assim, as relações históricas produzidas por homens e mulheres.

Desse modo, categorias e conceitos que representam um espectro de igualdade, liberdade e participação ativa na definição das diretrizes da sociedade, tais como democracia e cidadania, são largamente utilizados pela organização social capitalista e por seus agentes (estatais ou privados) como realidade existente - experienciada pelo sufrágio, pelo 
acesso à educação e por direitos universais - ou que, no limite, depende do esforço individual dos sujeitos para a sua plena realização.

No cerne da construção desse ideário, a educação moderna assume um papel fundamental. Segundo Arroyo (2003), a educação escolarizada, invenção da sociedade moderna capitalista, torna-se o principal vetor de cidadania para as classes dominantes. A cidadania compreendida como progresso, como avanço da barbárie à civilização, como participação política sob a racionalidade do projeto burguês de sociedade foi (e tem sido) propalada pela pedagogia moderna como mecanismo estratégico na promoção dos sujeitos à condição de cidadania. Entretanto, a cidadania sob os auspícios da sociedade capitalista "é vista como aceitação da obrigação moral para o convívio harmônico com seus semelhantes. Educar para a cidadania se reduz a cultivar o senso de valor moral em cada indivíduo, na criança e nos jovens sobretudo" (ARROYo, 2003, p. 58).

Nessa perspectiva, as relações sociais e o pensamento hegemônico buscam instituir a cidadania como um vir-a-ser, baseado na experiência individual de qualificação do discurso ou do entendimento, ou, em termos progressistas, no desenvolvimento da consciência.

A socialização desencadeada pelo processo civilizatório do modo de produção capitalista condiciona os sujeitos e as diferentes classes em uma determinada ordem, em relações, hábitos, valores e saberes próprios das classes dominantes, tornando o conceito de cidadania em um axioma genérico e abstrato. Nesse sentido, o termo cidadania constitui-se como tutela, concessão das elites dirigentes por meio da assistência ou da filantropia ou como outorga do Estado, suprimindo o caráter classista da luta pela realização de uma vida digna e por um outro tipo de sociabilidade em que seja possível a realização de uma cidadania plena.

Entretanto, a atual conjuntura é extremamente rígida e destrutiva, até mesmo em relação aos direitos construídos, às duras penas, no bojo do conflito entre trabalho e capital, sob os limites dos condicionantes deste último. Ou seja, até mesmo a cidadania nos limites do capital se encontra ameaçada. A crise estrutural do capital e, portanto, o esgotamento de suas possibilidades civilizatórias materializam uma lógica perversa cuja realização da razão de ser do capital (auto-expansão e acumulação) afirmam a desigualdade não só como um produto do sistema, mas uma necessidade.

O fundamentalismo de mercado materializado pela ideologia neoliberal compreende a intervenção estatal como um mecanismo de 
coerção e de supressão do livre desenvolvimento dos homens e da sociedade, como atesta Hayek (1990). Para a realização de um modelo de produção da realidade social em que a concorrência constitui-se como lei natural e que a mão invisível do mercado é o almirante da nau societal, a desigualdade e a afirmação da pobreza não precisam mais ser veladas pelos preceitos da cidadania.

Hayek (1990, p. 110) enfatiza que, embora a concorrência seja uma lei natural e que a mobilidade social dependa do indivíduo, a riqueza pertence a poucos.

Sem dúvida, no regime da concorrência, as oportunidades ao alcance dos pobres são muito mais limitadas que as acessiveis aos ricos. Mas mesmo assim em tal regime o pobre tem uma liberdade maior do que um indivíduo que goze de muito mais conforto material numa sociedade de outro gênero (sic). No regime de concorrência, as probabilidades de um homem pobre conquistar grande fortuna são muito menores que as daquele que herdou sua riqueza. Nele, porém, tal coisa é possível visto ser o sistema de concorrência o único em que o enriquecimento depende exclusivamente do individuo e não do favor dos poderosos, e em que ninguém pode impedir que alguém tente alcançar esse resultado. (Grifos meus)

A proposição de um capitalismo duro e livre de regras não só tem instituído como também tem expressado que a desigualdade - e, portanto, a não cidadania, a destruição dos direitos, a exclusão, a fome, a miséria, o desemprego etc. - é um valor positivo e imprescindível (ANDERSON, 2000). A ofensiva teórico-política que o neoliberalismo produziu sobre o Estado-de-bem-estar e sobre as experiências socialistas apresenta como metas claras a destruição dos direitos sociais e de parte significativa da força humana de trabalho e dos mecanismos de organização política da classe-que-vive-do-trabalho. Tal ofensiva se apresenta como a desconstrução de um ideário gestado no interior das próprias contradições dessa sociedade, como é o caso da cidadania.

Muito embora importantes análises e investigações sobre o processo de reestruturação do mundo do trabalho, ${ }^{1}$ das políticas neoliberais ${ }^{2} \mathrm{e}$ da globalização econômica ${ }^{3}$ constatem que os efeitos das fraturas do modo de produção capitalista estejam atingindo, inclusive, os países centrais e hegemônicos, produzindo bolsões de miséria, desemprego, conflitos civis de toda ordem e ataques terroristas, são nos países dependentes e periféricos que seus efeitos são mais drásticos. 
Nem mesmo os ideais da cidadania burguesa se efetivaram no Brasil ante sua condição de dependência e subordinação em relação ao capital forâneo. Para Buffa (2003, p. 28), o Brasil tem se constituído como uma sociedade autoritária e hierarquizada, em que os direitos do homem e do cidadão não existem.

Não existem para a elite, de vez que ela não precisa de direitos porque tem privilégios. Está, pois, acima deles. Não existem para a imensa maioria da população - os despossuídos -, pois suas tentativas de consegui-los são sempre encaradas como problema de polícia e tratadas com todo rigor do aparelho repressor de um Estado quase onipotente. (CHAUI, 1986, apud BufFA, 2003, p. 28)

A desertificação social (ANTUNEs, 2004) provocada pelo atual estágio destrutivo do capitalismo tem no seu escopo um profundo processo de reforma do Estado e, portanto, das políticas sociais desenvolvidas por este. O desígnio de integrar-se à economia mundialmente globalizada de forma "autônoma" e competitiva tem servido de argumento legitimador de tais reformas. Desse modo, as reformas do aparelho do Estado significam a incorporação da lógica de gestão dos setores privados e a privatização dos setores da economia em que o aparelho estatal intervém.

A reestruturação dos Estados nacionais das diversas nações teve como marco fundamental os acordos decididos durante o Consenso de Washington. Tais acordos apresentaram a seguinte programática a ser executada pelos países:

ajuste fiscal; redução do tamanho do Estado; fim das restrições ao capital externo (eliminar todo e qualquer empecilho ao capital especulativo ou vindo do exterior); abertura do sistema financeiro (fim das restrições para que as instituições financeiras internacionais possam atuar em igualdade de condições com as do país); desregulamentação (redução das regras governamentais para o funcionamento da economia); reestruturação do sistema previdenciário. (COGGIOLA; KATZ, 1996, p. 1996)

Conforme observa Ricardo Antunes (2004, p. 44), a execução do programa de enxugamento e modernização do Estado busca materializar o projeto de integração subordinada à ordem, destruindo boa parte do que foi criado durante a era Vargas. A privatização das empresas estatais, a redução do parque produtivo nacional e a flexibilização e desconstrução dos direitos trabalhistas são a tônica do processo de reforma do Estado. 
A consolidação da tese de que o Estado interventor é prejudicial ao livre desenvolvimento das forças econômicas, uma expressão de totalitarismo político e econômico, é parte do receituário neoliberal, afirmado categoricamente por Hayek (1990) como mecanismo de servidão e determinação sobre o processo de livre desenvolvimento das forças produtivas e, portanto, da expansão das taxas de lucro do capital. Desse modo, seria necessário instituir um Estado mínimo que dê suporte, legal e estrutural, ao "livre desenvolvimento das forças sociais". Sob esses condicionantes, um sistema de serviços sociais pode até ser exercido pelo Estado, "desde que a organização de tais serviços não torne ineficaz a concorrência em vastos setores da economia" (НАYEK, 1990, p. 59).

O Estado mínimo constitui-se, então, como parte da pragmática neoliberal que se materializa como mecanismo voltado para a recomposição das taxas de lucro e de legitimação do status quo. Entretanto, as realizações de seus objetivos são entravadas pelas contradições explicitadas pelas profundas mazelas sociais e, conseqüentemente, pela resistência dos setores excluídos e oprimidos, ou seja, a imensa maioria que compõe a classe que vive de seu trabalho. Assim, a deserção do Estado significa a supressão da cidadania tanto da agenda do Estado como de quem depende, no plano imediato, de suas políticas.

O caráter mínimo do Estado se apresenta na deterioração das políticas sociais, na incapacidade de conter o desemprego em massa, na baixa aplicação de recursos públicos para educação e a saúde, na contenção de gastos com os servidores públicos, enfim, em um conjunto de medidas tomadas sempre de forma autoritária, muitas vezes passando por cima da Constituição do país, sempre em prejuízo do conjunto da nação. (DEL PINO, 2002, p. 73)

O conjunto de ações que compõem a reforma do Estado se efetiva mediante reformas focalizadas na legislação do país referente à economia e às relações entre trabalho e capital, na previdência e nas políticas sociais (saúde, educação, moradia, reforma agrária). O denominado processo de modernização do aparelho estatal tem como principal meta realizar um conjunto de reformas nos diversos campos de intervenção do Estado, de maneira que estes sejam integralmente privatizados - exemplo disso, os leilões responsáveis pela privatização das telefônicas e de outras empresas estatais durante o governo $\mathrm{FHC}$ - ou, então, que sejam adequados aos princípios do mercado, tendo como lógica central a produtividade, 
eficiência, eficácia, relação equilibrada entre custo-benefício, pouco investimento e maior retorno.

O processo de mercadorização de setores importantes como a saúde e a educação, por exemplo, não ocorre no Brasil pelo repasse imediato à iniciativa privada, mas sim pela desqualificação ideológica e material do serviço público, pelo desmantelamento das escolas, hospitais e universidades, terceirização de serviços, redução do financiamento e transferência de responsabilidade para a "sociedade civil" (descentralização/desconcentração) e aplicação do dinheiro público em setores privados ligados a estas áreas (editoras, fundações, empresas farmacêuticas etc.).

Desse modo, os direitos conquistados, que vinham sendo objeto de lutas dos trabalhadores, vão sendo desmantelados a ponto de não mais existirem, tanto quantitativa quanto qualitativamente. Sob as relações construídas na atual conjuntura, tais direitos não se impõem pelas necessidades e demandas das classes subalternas, mas sim pelos determinismos do capital.

A "entrada" dos países na economia globalizada é condicionada pelos organismos internacionais, especialmente o Banco Mundial (BM) e o Fundo Monetário Internacional (FMI), que impõem duros mecanismos aos países que solicitam cooperação, gestados - quase sempre sem buscar compreender a realidade dos países que buscam os empréstimos -, por consultores e financistas do grande cassino do mercado financeiro, capitaneados pelo Tesouro Nacional dos Estados Unidos (Stiglitiz, 2002).

Dentre as condicionalidades ${ }^{4}$ que os organismos financeiros internacionais estabelecem às nações dependentes estão as reformas educativas. A educação conforma-se como ponto estratégico na formação de um novo trabalhador e, portanto, de um novo homem. O processo de reestruturação do mundo do trabalho (reengenharia, novas tecnologias, novas formas de gestão do trabalho, just in time, kanban, flexibilidade etc.) cria uma série de novas exigências para a formação da força humana de trabalho, incidindo na intensificação do processo de extração de maisvalia e na construção da necessidade de educação permanente. Desse modo, as políticas educacionais apresentam a necessidade de reformar os sistemas de educação, no sentido de que estes dêem conta de suprir as necessidades do mercado de trabalho globalizado, formando uma mãode-obra capaz de elevar sua nação, competitivamente, à globalização .

Nessa perspectiva, as proposições e as formas educativas que visavam à formação emancipada para a cidadania são substituídas pelas 
necessidades, imperativas, de escolarização para a empregabilidade, muito embora os documento oficiais (parâmetros curriculares nacionais, diretrizes curriculares, projetos de cooperação com os organismos financeiros) apresentem a educação como sinônimo de construção da cidadania. Cidadania, nesses termos, ainda está vinculada à outorga do Estado e não à produção ativa de condições dignas de vida e trabalho por parte dos homens e das mulheres. É, portanto, um termo abstrato sem materialidade, objeto de uma educação restrita.

Mas se os alunos são "objetos" da cidadania de que estão alheios, quem são seus "sujeitos"? Quem produzirá, no interior dos processos de ensino-aprendizagem, a cidadania? Se os professores são os "sujeitos" do processo de promoção da cidadania, serão eles mesmos cidadãos? Em que medida as condições objetivas e subjetivas do trabalho docente podem indicar os trabalhadores da educação como cidadãos? Serão também os professores "objetos" de projetos alheios, de reformas que produzem a não-cidadania?

Estas questões norteiam as reflexões desenvolvidas neste texto, embora seja um espaço limitado para materializar os nexos constitutivos dessa relação, em virtude da própria natureza de um artigo. Desse modo, proponho refletir sobre o caráter ideológico e concreto da cidadania no interior do discurso pedagógico; as reformas educacionais da década de 90 e a reorientação da cidadania, bem como a supressão da cidadania dos trabalhadores docentes; busco ainda apresentar o processo de construção da cidadania no interior dos conflitos entre classes e na luta pela escola pública e gratuita para todos.

\section{DA CIDADANIA OUTORGADA À EMPREGABILIDADE}

Segundo Buffa (2003), os termos "cidadão" e "cidadania", tal como os compreendemos hoje, são produto do processo de construção da sociedade capitalista. A ascensão do liberalismo como teoria do conhecimento ou como ideologia oficial, o desenvolvimento da razão iluminista e a crença no esclarecimento dos homens por meio da razão e, principalmente, o avanço das forças produtivas e das relações sociais de produção capitalistas constituíram a cidadania como termo que representa a condição humana de superação das amarras da antiguidade e sua elevação a sujeito de uma nova realidade. 
O desenvolvimento da indústria moderna, a "libertação" dos homens da condição de servos dos feudos para se tornarem servos do trabalho assalariado e a constituição da propriedade burguesa são aspectos materiais sobre os quais se estruturam novas formas de "organização política - o Estado moderno -, colocam os homens em novas relações com a natureza - a ciência moderna - e trazem alterações na organização do saber escolar - a escola moderna" (Buffa, 2003, p. 15). Sobre essas estruturas, articula-se o ideário liberal que exprime, teoricamente, os interesses da burguesia. No bojo do ideário liberal, liberdade e igualdade são compreendidas e veiculadas como princípios naturais e condição inata dos homens.

As idéias de Locke são fundamentais na construção desse ideário. A concepção de que todos os homens são proprietários de si mesmos, de seu corpo, de sua força física e faculdades intelectuais estabelece a noção de que todos os homens são livres, pois são proprietários de si mesmos e, portanto, todos são, naturalmente, iguais. Entretanto, a igualdade propagada é a exercida nas relações de troca e pelo aparato jurídico.

O ideário liberal vela, portanto, as relações concretas entre as classes sociais, materializadas pelo conflito entre os donos dos meios de produção e os trabalhadores assalariados. A acepção fetichizada de igualdade e liberdade naturaliza relações construídas sócio-historicamente, buscando determinar, a priori, os processos de produção da desigualdade e exploração.

Tal ideologia escamoteia que aos trabalhadores não há possibilidade real de escolha. Esses, inevitavelmente, vendem sua força de trabalho em troca de salários aos capitalistas. Essa relação de troca é condição inerente à própria produção do capital em sua forma societária, sendo, portanto, necessário à constituição e reprodução das formas metabólicas do capitalismo e em sua constituição mesma como classe trabalhadora (MARX, 1980). Estabelece-se uma relação de dependência recíproca em que o trabalhador depende do capitalista para sobreviver como tal e o capital necessita da força de trabalho social para se produzir e reproduzir.

Assim, no interior das relações entre capital e trabalho, liberdade e igualdade para todos são argumentos ideológicos que escondem a verdadeira face de dependência e a profunda desigualdade que os trabalhadores assalariados têm em relação aos donos dos meios de produção. 
$\mathrm{Na}$ esteira dessas relações, a pedagogia moderna é constituída com base nos princípios liberais de igualdade e liberdade entre todos os homens. Nesse sentido, a educação torna-se pressuposto para a mobilidade social do indivíduo, desde que ele seja filho da elite ou tenha habilidades extraordinárias. Essa educação é responsável pela formação do cidadão. Entretanto, como observa Buffa (2003, p. 22), a educação foi (e tem sido) materializada de forma dualizada, estabelecendo, também, uma cidadania dual: a educação e a cidadania dos dirigentes, que ascendem aos altos estudos e se formam numa cultura geral; e a educação e a cidadania dos trabalhadores, ou seja, uma educação nivelada por baixo capaz de adaptar os sujeitos à ordem econômica, formando "o trabalhador disciplinado, disposto ao trabalho diligente e à frugalidade".

A ideologia burguesa, instaurada como ideal universal - como, por exemplo, a Declaração dos Direitos dos Homens e do Cidadão de 1789 -, apresenta os princípios responsáveis pela realização da cidadania, tida como direitos do homem, naturais e imprescindíveis: liberdade, propriedade e igualdade perante a lei. Nestes termos, o critério central de cidadania é a propriedade não só de si mesmo, mas, principalmente, dos meios de se produzir a vida material. Desse modo, é possível estabelecer formas hierárquicas de cidadania.

Há pois, no pensamento burguês, uma nítida separação entre proprietários e não-proprietários. Só os proprietários é que têm direito à plena liberdade e à plena cidadania. Aos não proprietários cabe uma cidadania de segunda ordem: enquanto cidadãos passivos, têm direito à proteção de sua pessoa, de sua liberdade e de sua crença, porém não são qualificados para serem membros ativos do soberano. (BUFFA, 2003, p. 27)

A promessa de que a educação elevaria os indivíduos à condição de cidadão consciente, racional e socializado, materializa um modelo de cidadania separada do seu caráter econômico e social, substituindo, ideologicamente, a luta pelos direitos sociais e pelas condições materiais por uma moralidade submissa às determinações sociais. Desse modo, a cidadania significa a adaptação funcional do indivíduo no interior da ordem social capitalista. Nesse sentido, desde a gênese do modo de produção capitalista, a educação para a classe trabalhadora serviria para a formação de uma mão-de-obra servil e docilizada, capaz de participar na sociedade como um "novo homem". 
Segundo Arroyo (2003, p. 36), a educação adquire uma centralidade política que, nas sociedades anteriores, era remetida à Igreja.

na nova ordem deveria ser a educação quem venceria a barbárie, afastaria as trevas da ignorância e constituiria o cidadão. Enfim, da educação se espera o milagre de configurar o novo homem livre para o novo mercado econômico, social e político. A pedagogia adquiriu, nas formas de representar o social, uma centralidade política nunca tida antes. Passou a ser pensada como mecanismo central na superação da velha ordem pela nova ordem. [...]. Uma representação que acabou ocultando a barbárie, o despotismo e a exploração, da nova ordem capitalista.

A educação tornou-se justificativa para a não-participação da classe trabalhadora no governo da sociedade e nos rumos da produção social. A ignorância, os vícios, as limitações intelectuais e a aculturação são alcunhas atribuídas aos trabalhadores, no sentido de desqualificá-los e legitimar a necessidade de uma sociedade governada pelas elites esclarecidas. A participação política, nessa perspectiva, só pode ser realizada por aqueles que atingem o padrão moral e racional exigidos.

Em síntese, a educação, a racionalidade que se exige da classe operária e das camadas populares para serem reconhecidos como membros da comunidade política é a negação da racionalidade operária e popular, ou a negação de sua capacidade de agir politicamente em defesa de seus interesses e não dos interesses da burguesia. (ARRoYo, 2003, p. 46)

A perspectiva de construção da cidadania por meio da educação não tem se constituído apenas como bandeira conservadora que busca socializar a classe trabalhadora em um caráter moralista e racional de cidadão, mas se tornou importante no interior das propostas progressistas de educação, enfatizando as possibilidades de conscientização que o processo educativo estabelece. Tais concepções invertem as questões de ordem material, buscando resolver nas idéias as contradições postas nos processos de produção da realidade, "deixando intocadas as condições materiais de existência a que estão submetidas as classes trabalhadoras" (ARroyo, 2003, p. 73).

Assim, a relação mecânica entre educação e cidadania caracteriza-se por seu aspecto conservador, abstrato e genérico, contribuindo, sobremaneira, para a manutenção da ordem e exclusão da cidadania para as maiorias. Como afirma Arroyo (2003, p. 39), 
a vinculação entre educação e cidadania, como precondição para a participação, vem agindo durante séculos para justificar a exclusão da cidadania, a condenação das camadas populares à condição de incivilizados, de não aptos como sujeitos de história e de política, e a legitimação da repressão e desarticulação das forças populares por teimarem em agir politicamente fora das cercas definidas pelas elites civilizadas como o espaço da liberdade e participação racional e ordeira.

Entretanto, a cidadania compreendida como o conjunto de direitos civis, políticos e sociais (PINSKY; PYNSKY, 2003) não pode ser entendida apenas como concessão das elites dirigentes ou como mecanismo de controle ideológico. É necessário submeter a análise da construção da cidadania sob a base concreta dos conflitos antagônicos entre classe trabalhadora e os donos dos meios de produção, compreendendo-a como expressão da luta não só por direitos sociais, políticos e civis nos limites do capitalismo, mas também pela construção de uma nova sociabilidade pautada por um ethos em que não haja exploração do homem pelo homem.

As lutas organizadas dos trabalhadores criaram condições, no seio das contradições da produção capitalista, para a conquista de direitos sociais importantes, como a saúde, a educação e os direitos trabalhistas. Tais conquistas amenizaram os efeitos da desigualdade social provocada pelo sociometabolismo do capital, especificamente, pela utilização do fundo público. Estas conquistas são fundamentais para a materialização de condições mínimas de dignidade aos trabalhadores sujeitos à exploração do mercado, ou dele excluído.

No entanto, a atual conjuntura de crise sistêmica do capital tem produzido mecanismos de gestão que possui como meta lançar sobre as costas dos trabalhadores o ônus da retração das taxas de lucro e de acumulação do capital (CogGiolA; KATZ, 1996).

A deserção do Estado, materializada pela privatização e desmantelamento dos serviços públicos, atinge brutalmente a parcela de trabalhadores mais afetados pelos efeitos sociais da produção capitalista: os desempregados, sem-tetos, sem-terras, miseráveis e toda ordem de excluídos. Nesse sentido, é possível afirmar que o Estado brasileiro tem construído a negação da cidadania para as suas maiorias.

Nem mesmo a educação, que fora, por um longo tempo, compreendida como promotora da cidadania (embora os documentos oficiais mantenham essa relação), escapa da racionalidade modernizante do 
capital. Os ideais de uma educação democrática, pública e gratuita, gestados, com entusiasmo, durante o período de reabertura democrática e consolidação da "Nova República", sucumbe diante da pragmática das agendas internacionais para a educação. Como observa Oliveira (2001, p. 113):

A defesa do ensino fundamental como condição para a cidadania participativa, principio ético orientador dessa luta no movimento social organizado ao longo de décadas, vem cedendo espaço aos argumentos em prol da escolaridade como meio de garantir a existência material imediata. [...] Com o crescimento do desemprego, cresce a procura pela educação como forma de se proteger, tanto da possibilidade da demissão quanto do próprio desemprego.

As reformas do Estado e as conseqüentes reformas educacionais representam um novo impulso da relação economia e educação, sendo a última subordinada à primeira. A retomada das teses do capital humano sob a roupagem da formação de um novo trabalhador mais flexível, integrado aos interesses da empresa, com habilidades cognitivas e de organização coletiva - o cognitariado que substitui o proletariado - são exigências das quais a escola precisa responder e os sujeitos precisam buscar individualmente (FrigotTo, 1998).

Assim, a educação não tem como princípio promover a cidadania, mas sim a condição de ser ou não absorvido pelo mercado de trabalho. Desse modo, nem os alunos são compreendidos como cidadãos possuidores do direito a uma formação humana qualificada, nem tampouco os executores dessas reformas - os professores e as professoras - são chamados a concebê-las. Ao contrário, são vítimas das reformas como observam Barreto e Leher (2003), Leher (2002), Oliveira (2001 e 2003) e Silva (2001).

IMPACTOS DA REFORMA EDUCACIONAL NO BRASIL SOBRE O TRABALHO DOCENTE: A SUPRESSÃO DA CIDADANIA

Há uma vasta literatura que aborda a reforma educativa no Brasil, analisando-a como parte do processo de reforma do Estado e dos ajustes estruturais determinados pelos organismos financeiros internacionais diante da crise do capital. As análises que recorrem a um olhar crítico sobre a questão afirmam que as proposições das reformas educacionais 
têm como objetivo dar respostas eficientes às exigências de qualificação emergentes no contexto da reestruturação produtiva e da globalização da economia.

Estamos diante de um processo de reestruturação do mundo do trabalho e, portanto, das exigências que a inovação tecnológica, os processos de reengenharia e as formas flexíveis de gestão do trabalho exercem sobre os trabalhadores, no sentido de produzir maiores níveis de exploração, mediados, principalmente, pela substituição do trabalho vivo pelo trabalho morto. Estas mudanças promovem profundas alterações nas formas de ser do trabalhador, qualificando alguns ramos produtivos e desqualificando ou mesmo fazendo desaparecer outros (ANTUNES, 2003). À produção de novos padrões de exploração da força humana de trabalho e de extração de mais-valia une-se a ampliação, sem precedentes na história, do desemprego estrutural, do emprego precário ou terceirizado.

Nesse contexto, a educação assume um papel central, qual seja, a formação para o trabalho, em que a educação básica seja responsável pela conformação de indivíduos que se adaptem mais rapidamente às mudanças no processo de trabalho, produzindo habilidades de aprender a aprender; e de integração social, responsável por retirar da marginalidade os setores economicamente em risco e prevenindo os riscos de convulsões sociais (OLIVEIRA, 2001, p. 112).

As reformas educacionais para a América Latina e, conseqüentemente, para o Brasil fazem parte do escopo de consolidação da globalização econômica e das políticas neoliberais. Sobre esse ponto, Barreto e Leher (2003, p. 39) afirmam:

A partir dessa premissa, os organismos internacionais e os governos fazem ecoar uma mesma proposição: é preciso reformar de alto a baixo a educação, tornando-a mais flexível e capaz de aumentar a competitividade das nações, únicos meios de obter o passaporte para o seleto grupo de países capazes de uma integração competitiva no mundo globalizado.

As linhas centrais das reformas educacionais nos países dependentes têm como linhas gerais de ação: descentralização/desconcentração; autonomia; aproximação da sociedade civil; reformulação dos currículos adequando-os à lógica das competências (aprender-aprender, aprenderser, aprender-fazer); reorientação da formação de professores; avaliação estandartizada com publicização de resultados; ${ }^{5}$ focalização das políticas; e destruição e/ou cooptação dos movimentos sindicais docentes. 
A adesão aos acordos internacionais, promovidos pelas agências financeiras, especialmente o Banco Mundial, deram a tônica das reformas educacionais executadas no Brasil. A Conferência Mundial de Educação para Todos, realizada em Jontiem (Tailândia, no ano de 1990) constitui-se como marco referencial da adequação do Brasil à agenda internacional para a educação. Ao se integrar ao grupo de países em desenvolvimento com problemas referentes à universalização da educação e alfabetização, grupo esse denominado de EFA-9 (Education for All), ${ }^{6}$ o Brasil assina a Declaração Mundial sobre Educação para Todos, que tem como principal objetivo atingir as necessidades básicas de aprendizagem sob as seguintes metas:

satisfação das necessidades básicas de aprendizagem; expansão do enfoque sobre educação; universalização do acesso à educação e promoção da equidade; concentração da atenção na aprendizagem e em ambiente propício para sua concretização; ampliação dos meios e do raio de ação da educação básica; fortalecimento de alianças; desenvolvimento de políticas contextualizadas de apoio; mobilização de recursos; e fortalecimento da solidariedade internacional. (UNICEF, 1990, apud VIEIRA, 2001, p. 64)

Essas metas são consolidadas por meio de uma série de medidas jurídico-administrativas, muitas delas aprovadas de maneira autoritária por meio de decretos e medidas provisórias ou por golpes aos projetos que a sociedade brasileira, de forma organizada e democrática, construiu nos diversos fóruns de defesa da educação pública, como foi o caso da Lei de Diretrizes e Bases da Educação Nacional de 1996.

As reformas não admitem que as comunidades educativas (professores, gestores, administrativos, pais, alunos e comunidade) determinem e decidam, democraticamente, as reformas necessárias ao processo de universalização da educação de maneira quantitativa e qualitativamente eqüidistante dos preceitos do mercado. Portanto, a comunidade educativa não é considerada cidadã, sujeito histórico capaz de definir política e socialmente os rumos da formação humana - ao contrário, são objetos das finalidades do capital. Nesse sentido,

a reforma educacional é discutida como um processo de mudança que se dá nos marcos do capitalismo, no âmbito da esfera pública e que pressupõe legitimidade dos envolvidos. Por perseguir, em geral, a otimização 
dos recursos disponíveis por meio de maior racionalidade administrativa, a reforma muitas vezes aparece como matéria técnica elaborada por peritos do assunto. (Oliveira, 2003, p. 21)

Os condicionantes das reformas atingem a proposição de uma educação pública, gratuita e de qualidade para todos, que atenda às demandas das classes subalternas por uma educação única, sem dualismos e fragmentações, que alie cultura geral e preparação para o mundo do trabalho de forma orgânica. Ao contrário, as reformas educacionais realizadas no Brasil durante a década de 90 significaram uma inflexão sobre as conquistas obtidas, por exemplo, no texto da Constituição.

Segundo Del Pino (2002) e Leher (2002), as reformas têm como parâmetros o estabelecimento de uma educação minimalista e desqualificada, embora escamoteada pelo discurso racionalizador de modernização e de qualidade total na gestão escolar (SiLva, 2001). O maior exemplo disso é a focalização das políticas educacionais e, portanto, do financiamento da educação aplicado exclusivamente no ensino fundamental, alijando as demais fases do ensino básico e o ensino superior. Segundo Barreto e Leher (2003, p. 47), as "reformas instauram um sistema educacional 'periférico', afastando a grande maioria do País do acesso ao conhecimento cientifico, tecnológico, artístico mais avançado".

A educação realizada sob os preceitos do mercado se empobrece, se estreita e se afasta diametralmente da perspectiva de um projeto educativo que tenha como eixo norteador a formação humana para uma verdadeira cidadania, o avanço da consciência sobre as contradições políticas, econômicas, culturais e sociais.

Um dos grupos sociais mais afetados pelas reformas educacionais são os trabalhadores docentes. As reformas educacionais que vêm sendo realizadas desprezam os saberes adquiridos no processo de realização do trabalho; instituem currículos centralizados, separando concepção de execução do trabalho docente e transformando-o em tarefa desqualificada e estranhada; introduzem a lógica da concorrência por meio de processos avaliativos que servem para comparação objetiva entre os resultados educacionais das escolas e dos professores; intensificam o trabalho docente, não somente aumentando a jornada de trabalho, mas, principalmente, instituindo a qualificação/certificação permanente como requisito da função e materialização das reformas; minimizam os processos de formação por meio de políticas de aligeiramento da formação docente, formação 
entendida como aquisição de novas informações, separando o ensino da pesquisa e da extensão e propondo novas tecnologias para efeito de redução de custos; ${ }^{7}$ e atacam os movimentos sindicais dos trabalhadores da educação, acusando-os de corporativos. ${ }^{8}$

A consolidação de uma imagem negativa dos professores aliada às estratégias de alienação do trabalho docente vem sendo articulada a mecanismos de controle externo político-ideológico da formação e atuação profissional.

Essas providências, adotadas na sua totalidade pelo governo Cardoso, a partir de 1995, constituem triangulação que aponta para um controle sem precedentes das metas estabelecidas para a educação brasileira: a compreendida pelo "currículo centralizado" (parâmetros e diretrizes com "tradução" para os professores, alijados da sua concepção), sustentando modalidades de "avaliação unificada", centradas nos produtos e nos indicadores quantitativos (SAEB, ENEM, Provão), duas pontas ligadas pelos programas e material de educação/ensino a distância (TV Escola, ProInfo, Proformação etc.), caracterizados pelo uso intensivo das tecnologias da informação e da comunicação (TIC). (BARRETO; LeHER, 2003, p. 51)

Juntamente às ofensivas das recentes reformas educacionais estão presentes os processos de proletarização do trabalho docente aprofundado desde meados do período militar - processos desencadeados pelas propostas tecnicistas que instituem nos processos educativos a divisão técnica do trabalho (separação entre quem concebe e quem executa) e o arrocho salarial.

A crescente desvalorização social e econômica dos professores, bem como sua aproximação do restante das classes trabalhadoras, tem, no entanto, produzido a configuração de novas identidades políticas no seio dos enfrentamentos entre trabalhadores da educação e Estado, na luta por condições dignas de vida e trabalho e também pela realização de uma educação pública, gratuita, estatal e de qualidade para as maiorias.

No interior desses embates, são materializados elementos concretos de luta pela realização da cidadania, cujos diferentes indivíduos se reúnem como um sujeito coletivo capaz de, pelo enfrentamento e pela resistência, definir rumos para as políticas educacionais, especificamente, e para as sociais em geral. 
O CONFLITO ENTRE CLASSE E A LUTA PELA EDUCAÇÃO COMO DIMENSÕES DA CONSTRUÇÃO DA CIDADANIA

A luta pela cidadania não é uma categoria abstrata nem tampouco um idealismo liberal. Na medida em que as lutas pelos direitos sociais entraram na agenda dos movimentos anti-sistêmicos e constituírem-se como parte integrante das mobilizações dos movimentos operário e social, a cidadania adquiriu um conteúdo classista. Em outras palavras, a organização política dos trabalhadores em torno da luta pela instauração da democracia e da cidadania significa "um movimento de luta pelos direitos dos oprimidos, o 'poder do povo', o poder dos 'de baixo', o que não era outra coisa que a verdadeira origem do termo" (CoGGIOLA, 2003, p. 311).

Separar a noção de cidadania do conflito entre as classes sociais, tratando a todos como cidadãos do mundo globalizado, que exerce sua cidadania em qualquer prateleira dos grandes mercados previdenciários, da saúde e da educação, é esgotar as possibilidades de se compreender o verdadeiro conteúdo educativo da luta pela realização de direitos . Como afirma Mascarenhas (2001, p. 35):

A relação entre a constituição das classes sociais e a luta pela extensão dos direitos de cidadania tem-se dado por meio de uma ligação muito íntima. [...] E aqui é preciso novamente que tenhamos muita cautela, pois a pressão para a extensão dos direitos de cidadania teve e tem como pano de fundo os conflitos de classes. Sem querer reduzir todo tipo de conflito à caracterização de conflito de classe, o que é preciso salientar é a abrangência desse fenômeno e a pertinência de destacá-lo na caracterização dos conflitos nas sociedades contemporâneas.

No seio da organização política das classes subalternas, engendrase um processo de educação popular em que os sujeitos se encontram, identificam realidades, sofrimentos e aspirações e identificam-se como sujeitos coletivos. Educam-se politicamente e atuam no interior das contradições e das relações de poder dessa sociedade, no sentido de instituir a cidadania ativa, participativa e concreta. É no interior das práticas sociais e políticas das classes que se conquista a cidadania. Nesse sentido, a construção da cidadania caracteriza-se pelos

processos sociais através dos quais as camadas populares agem como sujeitos políticos de reivindicação, os processos mentais que são definidos 
e afirmados nos movimentos reivindicativos, as formas de organização que se fortalecem, o poder popular que aumenta, ou seja, o próprio processo político-pedagógico de construção da identidade popular que se dá no confronto povo-Estado. É daí que a democracia avança e se constrói. (Arroyo, 2003, p. 78)

As concepções que aliam educação e cidadania têm como sujeito do processo de promoção da cidadania os alunos que estão em fase de escolarização. No entanto, não se questiona se os professores, também sujeitos dos processos educacionais, constroem sua cidadania, se são, na acepção do termo, cidadãos possuidores de direitos civis, políticos e sociais.

As reflexões apresentadas apontam que os professores têm sofrido profundos processos de desqualificação, alienação e empobrecimento. Há uma aproximação cada vez maior dos professores ao restante da classe trabalhadora, não só em termos de condições objetivas, mas, fundamentalmente, na luta por uma sociedade mais justa e democrática.

As reformas educacionais da década de 90 e o conjunto das reformas do Estado têm destruído o oficio docente, aproximando-o de tarefas rotineiras de execução das determinações curriculares definidas por especialistas. Os processos de formação inicial e continuada são aligeirados, privatizados e esvaziados de reflexões sistemáticas, cabendo aos professores aprender o necessário para fazer e para aprender a aprender. Seus salários são aviltados e seus reajustes nunca superam os déficits em relação às perdas. Os professores são acusados de preguiçosos, incompetentes, articuladores de um "pacto corrupto" (BARRETO; LeHER, 2003, p. 48) e corporativistas, buscando opor pais e comunidade em relação aos professores.

Para as reformas educacionais realizadas pelos países da América Latina, dentre eles o Brasil, os professores são figuras centrais da intervenção política. Se forem dóceis e passíveis de cooptação, ótimo, se são resistentes é preciso flexibilizar.

Afinal, "todos sabem" que as escolas não são reformadas facilmente porque os professores são avessos às mudanças, não querem assumir responsabilidades e compromissos com os pais e os alunos pobres. Ademais, os planos de cargos e salários engessam a administração. Os custos da folha de pagamento aumentam ano a ano, mesmo quando não há reajuste, em função de critérios de progressão que não premiam o mérito e porque 
os professores podem-se aposentar com o salário integral, um privilegio descabido. Professores da carreira tendem a se acomodar e seus sindicatos, em geral oposicionistas, articulam-se com partidos de esquerda para proteger seus privilégios. Um grande desafio da reforma, portanto, é flexibilizar o trabalho docente. (BARRETO; LeHER, 2003, p. 40)

Todas essas ofensivas são formas de negar a cidadania para aqueles que são socialmente provocados a corroborar o processo de formação humana e de promoção de cidadania. Desse modo, se "esquece que as circunstâncias são alteradas pelos homens e que o próprio educador deve ser educado" (MARX; ENGEls, 1999, p. 12).

Nesse sentido, a aproximação das classes populares a partir da massificação da educação pública (CosTA, 1995) e a organização políticosindical dos professores tornaram-se importantes vetores da construção de uma identidade política na luta por melhores condições de vida e trabalho, que significa, no limite, a realização de uma educação pública, gratuita e com qualidade para todos. Essa perspectiva de aproximação, objetiva e subjetiva, do restante da classe trabalhadora desmistifica a imagem de corporativismo tão propagada por governos e meios de comunicação e apresenta os professores como sujeitos coletivos que se organizam e lutam pela realização plena dos direitos.

Vale salientar o quanto é importante para a educação da classe trabalhadora a reivindicação da garantia do ensino público, gratuito e de boa qualidade. Essa é uma bandeira que não interessa apenas aos profissionais da educação, que são aqueles que mais intensamente a têm difundido, mas interessa a todos que se comprometam com uma sociedade mais justa e democrática. Muitas vezes a abrangência desta bandeira não é percebida, parecendo ser um aspecto específico da luta dos trabalhadores organizados da área da educação. No entanto, essa tem um caráter bastante amplo e um poder de aglutinação que em muitos momentos tem sido pouco potencializado. Garantir a todos o acesso à educação e garantir à classe trabalhadora uma formação ampliada (formação geral, formação profissional e educação política) significa contribuir para a construção de uma vida social mais digna. (MASCARENHAS, 2004, p. 27)

Os processos de luta pela educação e pela democratização do saber se configuram como um dos campos avançados das lutas populares. Desse modo, as lutas pela realização de uma escola digna, com professores 
valorizados econômica e socialmente, são constituintes da história da construção da cidadania.

A resistência dos sindicatos docentes da América Latina em relação às reformas educacionais de cunho liberal apresenta o movimento sindical docente como a organização política de trabalhadores que mais têm tornado explícito os conflitos entre capital e trabalho, superando, por vez, a ação dos sindicatos metalúrgicos.

Conforme observam Gentili et al. (2004), as reformas educacionais desenvolvidas na América Latina durante as últimas décadas têm provocado um cenário de conflitividade, apresentando os trabalhadores docentes, organizados em seus sindicatos, como os principais sujeitos políticos na resistência à imposição da visão neoliberal de educação.

Esses conflitos se evidenciaram, principalmente, por meio de paralisações e greves. Entre o período de 1998 e 2003 foi computado um total de 4.802 dias de paralisação em toda a América Latina. O Brasil é o terceiro país em número de conflitos, paralisações e duração das greves.

Os movimentos sindicais docentes vêm, desde o final da década de 70 , se tornando um dos principais sujeitos políticos da sociedade brasileira. A capacidade de mobilização, a organização das escolas como local de trabalho que articulam milhares de trabalhadores em cada estado do país e a perda da centralidade do operariado podem indicar a conformação de um novo lócus de organização política dos trabalhadores.

Desse modo, a luta pela educação tem-se tornado um aspecto fundamental na construção da cidadania. A democratização da educação pública, gratuita de qualidade socialmente referendada é uma bandeira da organização político-sindical dos trabalhadores em educação e de todos os trabalhadores em geral. Nesse processo, a necessária participação, ativa, dos agentes centrais do processo educativo - os professores -, na luta pela instituição da cidadania da classe trabalhadora, significa a construção de suas próprias cidadanias.

\footnotetext{
ABSTRACT

This article aims to discuss the impact of the Brazilian educational reforms developed since the 1990s on the building of the citizenship for workers in the teaching field. To do so, educational reforms are situated in the wider context of the crisis of capital and the restructuring of their forms of exploitation, as are
} 
State reforms resulting from neo-liberal politics, responsible for robbing workers of their hard-won rights. In addition, I also seek to reflect on the contradictions of the discourse on the relationship between education and citizenship. And, finally, I point towards the building of citizenship as a product of the class struggle and the achievement of educational worker's citizenship as a result of the political-trade union struggle for a public, free, state and quality education for the masses.

Keywords: Teaching. Citizenship. Education reforms. Political organization.

\section{NOTAS}

1. Ver Antunes (1999) e Rifkin (1995).

2. Antunes (2002), Coggiola e Katz (1996) e Anderson (2000).

3. Ver Meszáros (2002), Stiglitz (2002) e Chesnais (1996).

4. Segundo Stiglitz (2002), condicionalidade é o conjunto de imposições que o BM e o FMI determinam sobre as nações que solicitam sua "cooperação". São medidas de ordem político-econômicas que atingem não só o sistema financeiro e produtivo, mas também áreas como a previdência, saúde e educação.

5. Segundo Afonso (2000), a avaliação estandartizada criterial com publicitação de resultados são mecanismos de controle sobre a materialização das políticas neoliberais de educação. Seus dados são publicados como critério de comparação entre sistemas, escolas ou mesmo professores, no sentido de instalar a lógica da concorrência em educação.

6. Ainda fazem parte desse grupo Bangladesh, China, Egito, Índia, Indonésia, México, Nigéria e Paquistão, além do Brasil.

7. Ver Dourado (2001).

8. Barreto e Leher (2003, p. 50).

\section{REFERÊNCIAS}

AFONSO, A. J. Avaliação educacional: regulação e emancipação. 2. ed. São Paulo: Cortez, 2000.

ANDERSON, P. Balanço do neoliberalismo. In: SADER, E.; GENTILI, P. (Orgs.) Pós-neoliberalismo: as políticas sociais e o Estado democrático. 5. ed. Rio de Janeiro, 2000. p. 9-23.

ANTUNES, R. A desertificação neoliberal no Brasil (Collor, FHC e Lula). Campinas: Autores Associados, 2004. 
- Adeus ao trabalho: ensaios sobre as metamorfoses e a centralidade do mundo do trabalho. 9. ed. Campinas: Ed. Unicamp, Cortez, 2003.

. Os sentidos do trabalho: ensaio sobre a afirmação e negação do trabalho. 5. ed. São Paulo: Boitempo, 2002.

ARROYO, M. Educação e exclusão da cidadania. In: BUFFA, E. (Org.) Educação e cidadania: quem educa o cidadão? 11. ed. São Paulo: Cortez, 2003. p. 31-80.

BARRETO, R. G.; LEHER, R. Trabalho docente e reformas neoliberais. In: OLIVEIRA, D. A. Reformas educacionais na América Latina e os trabalhadores docentes. Belo Horizonte: Autêntica, 2003. p. 39-60.

BUFFA, E. Educação e cidadania burguesas. In: BUFFA, E. (Org.) Educação e cidadania: quem educa o cidadão? 11. ed. São Paulo: Cortez, 2003. p. 11-30.

CHAUI, M. Escritos sobre a universidade. São Paulo: Unesp, 2001.

COGGIOLA, O. Autodeterminação nacional. In: PINSKY, J.; PINSKY, C. B. (Orgs.) História da cidadania. São Paulo: Contexto, 2003. p. 311- 342. 1996.

; KATZ, C.. Neoliberalismo ou crise do capital? São Paulo: Xamã,

COSTA, M. C. V. Trabalho docente e profissionalismo. Porto Alegre: Sulinas, 1995.

DEL PINO, M. Política educacional, emprego e exclusão social. In: GENTILI, P.; FRIGOTTO, G. (Orgs.). A cidadania negada: políticas de exclusão na educação e no trabalho. 3. ed. São Paulo: Cortez, 2002. p. 65-88.

DOURADO, L. F. A reforma do Estado e as políticas de formação de professores. In: PARO, V. H.; DOURADO, L. F. Políticas públicas \& educação básica. São Paulo: Xamã, 2001. p. 49-58.

FRIGOTTO, Gaudêncio. Educação e formação humana: ajuste neoconservador e alternativa democrática. In: GENTILI, P. A. A.; SILVA, T. T. Neoliberalismo, qualidade total e educação: visões críticas. 6. ed. Petrópolis, RJ: Vozes, 1998. p. 31-92.

GENTILI, P. et al. Reforma educativa y luchas docentes en América Latina. Educação \& Sociedade. Campinas. Vol. 25 set./dez., n. 89, 2004. p.1251-1274.

HAYEK, F. A. O caminho da servidão. 5. ed. Rio de Janeiro: Instituto Liberal, 1990.

LEHER, R. Tempo, autonomia, sociedade civil e esfera pública: uma introdução ao debate a propósito dos "novos" movimentos sociais na educação. In: GENTILI, P.; FRIGOTTO, G. (Orgs.). A cidadania negada: políticas de exclusão na educação e no trabalho. 3. ed. São Paulo: Cortez, 2002. p. 145-176. 
MARX, K. Trabalho assalariado e capital. São Paulo: Global, 1980.

MARX, K.; ENGELS, F. Ideologia alemã. 11. ed. São Paulo: Hucitech, 1999.

MASCARENHAS, A. C. B. Educação para além da escola: o caráter educativo dos movimentos sociais. In: PESSOA, J. de M. (Org.). Saberes do nós: ensaios de educação e movimentos sociais. Goiânia: Editora da UCG, 2004. p. 15-28.

Classes sociais, movimentos sociais e cidadania: velhos paradigmas, novas perspectivas. Interação. Vol. 25 jan./jun., 2001. p. 31-40.

MÉSZÁROS, I. Para além do capital. São Paulo: Boitempo, 2002.

OLIVEIRA, D. A. Reformas educacionais e suas repercussões sobre o trabalho docente. In: OLIVEIRA, D. A. Reformas educacionais na América Latina e os trabalhadores docentes. Belo Horizonte: Autêntica, 2003. p. 13-38.

OLIVEIRA, D. A. Política educacional nos anos 1990: educação básica e empregabilidade. In: PARO, V. H.; DOURADO, L. F. Políticas públicas \& educação básica. São Paulo: Xamã, 2001. p. 105-122.

PINSKY, J.; PINSKY, C. B. (Orgs.) História da cidadania. São Paulo: Contexto, 2003.

RIFKIN, J. O fim dos empregos: o declínio inevitável dos níveis de emprego e a redução da força global de trabalho. São Paulo: Makron Books, 1995.

SILVA, M. S. P. Gestão e organização do trabalho na escola pública: práticas sociais em educação em Minas Gerais (1983-1994). In: PARO, V. H.; DOURADO, L.F. Políticas públicas \& educação básica. São Paulo: Xamã, 2001. p. $123-142$.

STIGLITZ, J. E. A globalização e seus malefícios. São Paulo: Futura, 2002.

WALLERSTEIN, I. Capitalismo histórico e civilização capitalista. Rio de Janeiro: Contraponto, 2001.

VIEIRA, S. L. Políticas internacionais e educação - cooperação ou intervenção? In: PARO, V. H.; DOURADO, L. F. Políticas públicas \& educação básica. São Paulo: Xamã, 2001. p. 59-90. 